\title{
Em busca das identidades e sentidos de pertencimento na sociedade da comunicação e do consumo
}

\section{Searching for identities and belonging meanings in the communication and consumption society}

\author{
Marcia Perencin Tondato \\ Doutora em Comunicação pela Escola de Comunicações e Artes da Universidade \\ de São Paulo (2004), Mestre em Comunicação pela Universidade Metodista de \\ São Paulo (1998). Graduada em Publicidade (1992) pela UMESP. Estágio de pós- \\ doutoramento na Universidade de Brasília (2015). Docente titular do Programa de \\ Pós-graduação em Comunicação e Consumo da Escola Superior de Propaganda \\ e Marketing - ESPM-SP. Linha de Pesquisa: Processos de recepção e contextos \\ socioculturais articulados ao consumo.
}

\section{RESUMO}

Por meio dos discursos dos sujeitos-indivíduos urbanos analiso a intersecção consumo-cidadania. O princípio é que, nas sociedades democráticas capitalistas, a cultura do consumo acontece em um contexto de "cidadania", sendo necessário compreendê-la como um "processo" determinado e limitado às práticas de pertencimento e identidade. A análise dos resultados da aplicação de questionários e entrevistas em profundidade teve como base o Discurso do Sujeito Coletivo e a Análise de Discurso de linha francesa. As conclusões apontam para a explicitação do consumo como constituinte das identidades, que proporciona o pertencimento na medida em que significa participação do indivíduo comum nos destinos da sociedade, ciente e agente de seu direito ao consumo simbólico e cultural, definido também pelo consumo material.

Palavras-chave: consumo; cidadania; identidade.

\section{ABSTRACT}

From the speeches of urbane individuals I analyze the intersection consumption-citizenship. The foundation is that, in the capitalist democratic societies, consumption culture occurs in a context of "citizenship", being necessary to understand it as a "process" determined and contented by the practices of belonging and identity. The analysis of the results of application of questionnaires and in-depth interviews took as a base the Collective Subject Discourse and the French Discourse Analysis. Conclusions point out comprehension of consumption as constituent of identities, promoting belonging feeling in so far it means the common individual participation in the destinies of society, aware and agent of his/ her right to symbolic and cultural consumption, also defined by material consumption.

Keywords: consumption; citizenship; identity. 
Nadaé dado, não há sentido nato, nem fixo. Os sentidos são construídos a partir das interações sociais, cujas transformações vêm sendo dinamizadas pelo estabelecimento definitivo da globalização e, principalmente, pelas tecnologias (novas e antigas). O resultado é um novo sensorium (no sentido benjaminiano) que nos tem conduzido a cenários adjetivados por: líquido, espetacular, múltiplo, híbrido, fragmentado. Sem mencionar os fenômenos 'programados', delineadores do mesmo cenário, como a produção em escala, a democratização dos meios, a progressão da secularização.

Um novo sensorium que se desenvolve mudando os parâmetros da vida em sociedade, promovendo até uma 'nova' cultura: a cultura do consumo (SLATER, 2002, p. 32), que (re)define práticas sociais, valores culturais, identidades e aspirações; sobrepondo-se às dimensões tradicionais como o trabalho, a cidadania, a cosmologia religiosa, o contexto familiar, a participação política.

Com o objetivo de entender esta 'nova' sociedade, orientada pelo mercado mas, ao mesmo tempo, cada dia mais desafiada por dimensões que exigem maior envolvimento e integração de seus membros - consciência ecológica, redes digitais de relacionamentos para citar algumas, realizei pesquisa junto à moradores de Brasília ${ }^{1}$, explorando a relação consumocidadania no âmbito do fazer cotidiano. Os dados coletados com a aplicação de questionários e realização de entrevistas foram analisados a partir do Discurso do Sujeito Coletivo ${ }^{2}$, agrupando semelhanças e separando as diferenças encontradas nas falas dos sujeitos-indivíduos, resultando um coletivo que reflete um conjunto de ideias importantes em um espaço social e cultural e momento histórico determinados (LEFEVRE e LEFEVRE, 2013.

Por que Brasília? Por se tratar de uma cidade jovem, praticamente um micro cosmo das grandes metrópoles brasileiras, agregando habitantes com memória recente de suas origens geográficas e culturais e uma intensa relação com a formação do Distrito $\mathrm{Federal}^{3}$, seu novo lar. Embora uma

1 Este artigo consolida dados coletados entre maio e agosto de 2013, em pesquisa realizada em Brasília como parte do projeto "A construção midiática do consumo e da cidadania: identidades e representações nos discursos televisivos ficcionais - mediações entre cotidiano, ideologia e cultura", com apoio FAPESP, processo 2012/20850-6. Resultados parciais foram apresentados e discutidos nos eventos: $4^{a}$ Conferência ICA América Latina - Brasília, 2014 (não disponível) e VI Colóquio Brasil-Estados Unidos de Ciências da Comunicação - XXXVII Intercom, Foz do Iguaçu, 2014, disponível em: http://www. intercom.org.br/papers/nacionais/2014/resumos/R9-0422-1.pdf

2 Deste ponto em diante, abreviado para DSC.

3 O Distrito Federal, situado na Região Centro-Oeste, é a menor unidade federativa brasileira, organizada em 31 regiões administrativas (RA). Em seu território, está localizada a capital federal do Brasil, Brasília. A palavra "Brasília" pode se referir ao DF como um todo ou apenas à RA-I, que é basicamente formada pelo Plano Piloto e pelo Parque 
cidade planejada, a não consideração de um desenvolvimento mediado pelas contingências características da vida que se vive "no dia a dia" resultou no crescimento periférico desordenado das "cidades satélites", habitadas hoje por descendentes dos "candangos", que vivem da prestação de serviço no Plano-Piloto, onde moram majoritariamente funcionários públicos. Grupos sociais diferentes, porém com algo em comum: a origem em outros estados, trazendo outras culturas, valores e vocabulário. Regionalismos que foram abrandados na cidade "em construção" mais do que em metrópoles como São Paulo, para onde a migração se deu por "ondas", integrando os "chegantes" a uma cidade com uma identidade já constituída, que buscaram seus "pares" nos bairros já estabelecidos.

Desse ponto de vista, Brasília foi tomada como universo por se tratar de um espaço de intersecção de culturas onde, eventualmente, se concretiza uma identidade "brasileira". Ainda que São Paulo responda ao aspecto da diversidade, já existe uma "identidade paulista", que, mesmo composta por várias vozes culturais, para que seja entendida como "brasileira" demandaria recortes muito específicos, ou uma amostragem mais abrangente. A realização do campo em Brasília possibilitou explorar a diversidade de forma mais objetiva, pela facilidade de acesso à diferentes grupos promovida pela ocupação espacial segmentada, característica das Regiões Administrativas. (figura 1 - Brasília e demais RAs).

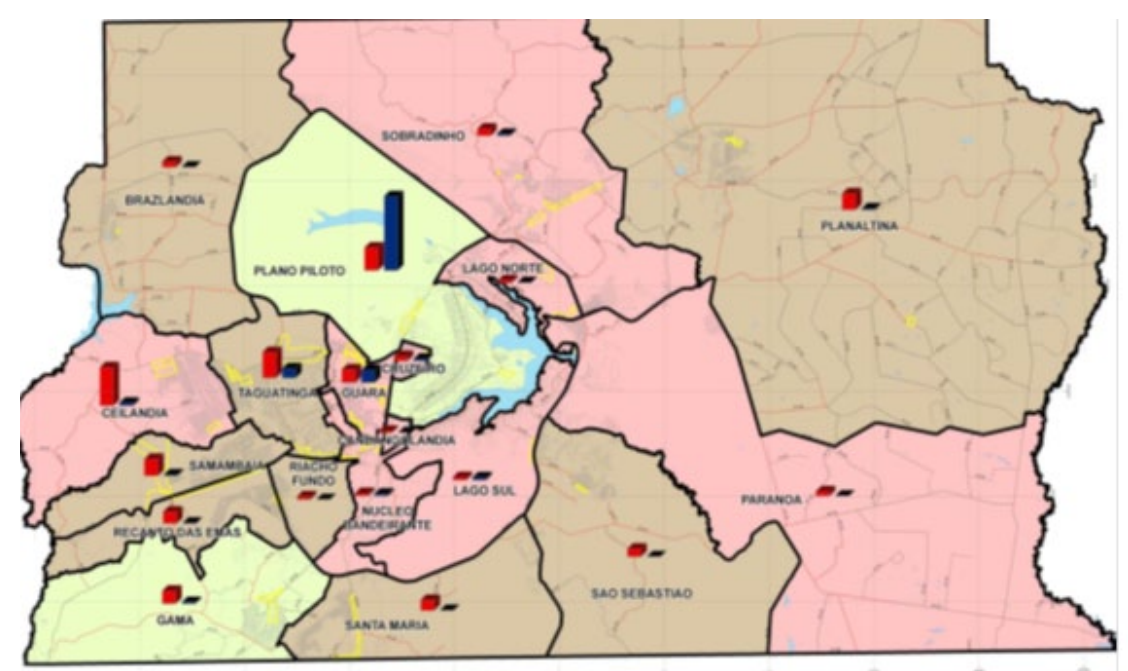

Figura 1 - Brasilia e demais Regiões Administrativas (RAs)

No decorrer dos $55^{4}$ anos de sua existência, a variedade cultural promovida pelas migrações oriundas de diversos estados da federação fez com que as diferenças linguísticas fossem "neutralizadas". Se com isso os

Nacional de Brasília. Antes de 1998, as RAs eram denominadas "cidades-satélites" (exceto o Plano Piloto, por ser o núcleo da região), termo proibido por decreto a partir daquele ano. $4 \quad$ Comemorados em 21 de abril de 2015. 
regionalismos foram neutralizados, o resultado foi um "sotaque", uma "fala", brasiliense caracterizado como um espaço de significados universais que, mais do que agregar, funde as identidades regionais. Brasília seria o melting pot brasileiro. Não São Paulo. Ainda assim, se o brasiliense tem uma identidade linguística própria, de um Brasil urbano, cosmopolita, ainda não é possível falar em uma identidade cultural própria, pela juventude da cidade.

Uma revisão de literatura: do consumo à cidadania na sociedade da mídia

O consumo de bens materiais, criticado como um dos males da contemporaneidade sob o rótulo do "consumismo", ocupa um espaço de interiorização muda da desigualdade social, da mesma forma que os processos de inclusão, ou exclusão, melhor dizendo. No âmbito econômico, "o consumismo chega quando o consumo assume o papel-chave que na sociedade de produtores era exercido pelo trabalho" (BAUMAN, 2008, p. 41). Para Baudrillard (2007, p. 206), com a generalização da lógica da mercadoria "o homem do consumo nunca se defronta (com) suas próprias necessidades, como também jamais se vê diante do produto do seu trabalho; também nunca se defronta com sua própria imagem: é a imagem dos signos que ordena". Isso transposto para a condição de pertencimento espacial na medida em que essa passa pela "identificação do sujeito com as atividades que realiza" (CERQUIER-MANZINI, 2010, p. 99), origina as problematizações que deram origem ao este estudo, sobre o que promoveria o pertencimento (espacial) na contemporaneidade.

No aspecto sociocultural, "o consumismo em aguda oposição às formas de vida precedentes, associa felicidade não tanto à satisfação de necessidades, mas a um volume e uma intensidade de desejos sempre crescentes, o que por sua vez implica o uso imediato e a rápida substituição dos objetos destinados a satisfazê-la" (BAUMAN, 2008, p. 44). ${ }^{5}$

Historicamente, a diferença marcante estabelecida no século XX foi a constituição da sociedade de massa. No século XIX, antes da sociedade industrial, o ócio dominava. $\mathrm{O}$ útil era definido pela racionalidade, advinda do trabalho, a ciência estabelecendo valores (Iluminismo), o restante era inútil, supérfluo. Na segunda metade do século XX, surge o conceito de consumismo a partir de uma ideia de acesso irrestrito à produção em massa, que passa a ser visto de forma positiva com a expansão dos serviços, abundância de bens e aburguesamento da classe operária (FREDERICO, 2008). A industrialização banaliza as comodidades, tornando-as mais acessíveis. "Nasce" uma nova sociedade, na qual a identificação se dá pelo consumo e não pela produção. Uma "sociedade, de consumidores", onde não há espaço para "o desejo

5 Tradução livre da autora. 
humano de segurança e os sonhos de um 'Estado estável' definitivo".

O consumismo que nasce com a urbanização amplia as diferenças sociais e exclusões na medida em que os camponeses e/ou os escravos recémlibertos, no caso do Brasil, vão para a cidade sem uma (in)formação que lhes possibilitasse a inclusão "cidadã" neste "novo ambiente", na medida em que isso demandava ter um emprego/capital para a satisfação das necessidades mais primárias - alimentação e saúde (antes, ainda que insuficientes, providas pelos senhores das terras). Sem mencionar a educação formal, que deverá ser universalizada.

O rompimento do fordismo no campo da produção não bastou para que se abrissem espaços reais para o exercício de possibilidades de independência simbólica e cultural, visto que produção e consumo não existem independentemente. Indo além, chego à Garcia Canclini (1996) que atribui ao neoliberalismo e ao uso feito da mídia as mudanças nas perspectivas do indivíduo como sujeito social, ou seja, o mercado destacando-se nas diversas relações que se lhe apresentam, colocando a globalização no centro do processo em desenvolvimento.

Se as relações com a cidade nos levam a pensar na cidadania, falar desta a partir de direitos assegurados por aparelhos estatais ou de uma origem geográfica é ser superficial. "O ato de votar não garante nenhuma cidadania se não vier acompanhado de determinadas condições de nível econômico, político, social e cultural" (CERQUIER-MANZINI, 2010, p 11). Também é pouco falar em direitos trabalhistas, universalização e gratuidade da educação e da saúde.

Exatamente minhas perspectivas para pensar o consumo como constituinte e constituído por uma "nova" cidadania, ou "identidade de pertencimento", conforme a argumentação que segue. Ocupo-me do consumo como uma prática de cidadania, o que implica aceitar a inexorabilidade da vivência em um contexto de mercado, promovendo um debate mais crítico, sem esquecer aquilo que de mais superficial o caracteriza na modernidade tardia: as condições externas que possibilitam a manipulação. O objetivo é repensar a cidadania como "estratégia política", reivindicando os direitos de aceder e pertencer ao sistema, como também de participar da reelaboração do mesmo, portanto daquilo do que queremos fazer parte.

No contexto da predominância do neoliberalismo num mundo globalizado, é pelo consumo que os diferentes aspectos da vida social se integram pela apropriação e usos que os indivíduos, antes trabalhadores agora consumidores, fazem dos produtos, antes “desejados” agora "possuídos” num 
ambiente regulado pelo cultural e pelo simbólico. Regulação salientada por Garcia Canclini (1996, p. 55) ao apontar que "nas sociedades contemporâneas boa parte da racionalidade das relações sociais se constrói, mais do que na luta pelos meios de produção, na disputa pela apropriação dos meios de distinção simbólica”. Disputa a partir da qual saliento o papel da mídia, responsável pela disseminação de signos e símbolos de maneira polissêmica e intertextual, a serem lidos conforme as intersecções dos fazeres cotidianos, recebendo as influências, mas ao mesmo tempo fazendo parte da constituição das identidades.

Um cenário que tem na televisão um ator primordial na geração de uma visão de mundo resultante da integração econômica, redução dos Estados-nação, fusão de tecnologias, imposição de mecanismos de livremercado, enfim, mostrando a reorganização de uma vida social condicionada por novas relações globais que, por sua vez, atravessam a cultura de massa, interiorizando relações de poder. Entretanto é preciso contemporizar o que está em jogo e como está sendo jogado, para que a chegada deste caminho não seja uma forma diferenciada de dominação, configurando-se o que Baudrillard (2007) conceitua como substituição do mito da igualdade pelo mito da felicidade, sem promover uma real inserção na cidadania de direito.

Desse cenário fazem parte novas dinâmicas sociais, originadas de diferentes conjunturas estruturais, com ênfase do simbólico nas relações sociais, com o global e o local influenciando-se reciprocamente. Entre as 'novidades', destaca-se o uso dos bens de consumo na especificação das relações sociais. Mercadorias, e respectivas marcas, são utilizadas como demarcadores de posição, transformando-se em lócus de luta pela mobilidade social, representando para as classes mais baixas um alvo a ser conquistado enquanto as elites trabalham em sua defesa, criando obstáculos concretos e simbólicos.

Uma transformação que também traz imbricado o amadurecimento de uma cidadania de um indivíduo que antes se remetia principalmente a direitos cívicos e agora reivindica o reconhecimento das diferenças, mas também de quem é cobrada a preservação do planeta. Direitos e deveres 
que se expressam entre o acesso financeiro e a qualidade do que é ofertado, promovendo a ampliação de mercados, que agora atingem todas as camadas sociais.

É preciso lembrar ainda que as práticas comunicacionais cada vez mais interpelam as construções de sentido e estabelecimento das dimensões sócio identitárias do cotidiano. Participar da sociedade midiática e ser consumidor de bens e serviços tornam-se atividades culturais, naturalizando demandas hegemônicas, sendo o cotidiano o lugar onde se constitui o significado das palavras, a partir da circulação das formas simbólicas, permitida pela consciência possível, resultante de uma ideologia, que é, por sua vez, impregnada de estereótipos e preconceitos. Entretanto, as pessoas não se sentem parte de um todo, por ele responsáveis. Acreditam que suas ações não tenham repercussão, dando espaço para infindáveis campanhas de mobilização, sem resultados efetivos de mudanças.

Mapeando o campo - conhecendo o universo, delineando o perfil dos entrevistados

A referência desse estudo foi a intersecção consumo-cidadania a partir da comunicação como recurso instrumental e metodológico, tomando como referência o discursivo e a dialogia que caracterizam as trocas sociais. Por meio da amostragem não probabilística por cotas, definidas pelo tempo de moradia em Brasília e idade, foram aplicados 150 questionários, contemplando o Plano Piloto e três outras Regiões Administrativas. ${ }^{6}$

Além do mapeamento do consumo midiático $^{7}$, os questionários apresentavam três perguntas abertas para coletar as percepções sobre consumo e cidadania, como base para o trabalho com o DSC que teve como princípio que toda representação é uma representação de um objeto e também de um sujeito (MOSCOVICI, 2012) na medida em que é resultado de "construções mentais elaboradas coletivamente pelos sujeitos a partir de seus referentes culturais". Como tal "é uma forma de conhecimento socialmente elaborada e partilhada, com um objetivo prático, e que contribui para a construção de

6 A pesquisa aqui apresentada foi realizada no Plano-Piloto; em Taguatinga, oficialmente a RA mais antiga; Ceilândia, a mais populosa e Paranoá, originalmente um acampamento dos tempos da construção da represa (década de 1950) que resistiu à erradicação, sendo que em 2013, 45.613 das pessoas que ali vivem ainda não têm escritura de suas casas. Disponível em: http://www.lugarcerto.com.br/app/402,61/2013/08/09/ interna ultimas, $47227 /$ justica-anula-registro-do-paranoa-e-terracap-podera-regularizar-area. shtml. Acessado em 14/out/2013.

$7 \quad$ Por razões de extensão, neste artigo priorizei os resultados da coleta do DSC e das entrevistas em profundidade. 
uma realidade comum a um conjunto social", que servem para orientar os comportamentos e práticas individuais e coletivas (JODELET, 2001, p.22).

Paralelamente, foram realizadas entrevistas focalizadas, ${ }^{8} \mathrm{em}$ total de $16(9 \mathrm{M} \mathrm{e} 7 \mathrm{H})^{9}$, amostradas por intencionalidade, com filtro de idade, escolaridade e local de moradia. As entrevistas foram gravadas, transcritas e sintetizadas em quadros construídos a partir dos objetivos ${ }^{10}$ da pesquisa, com vistas a identificar as formações discursivas da fala do receptor. A análise foi realizada com base na $\mathrm{ADF}$.

A distribuição quantitativa dos entrevistados delineia um cenário característico de um movimento que teve início nas ultimas décadas do século XIX decorrente da seca no Nordeste e que se repete a cada momento de desenvolvimento econômico brasileiro - extrativismo, industrialização com a inclusão de migrantes de outros estados. A maior parte reside há mais de 16 anos em Brasília (141/150), enquanto 31 são lá nascidos e os demais têm origem distribuída nos diversos Estados brasileiros. Das 16 pessoas entrevistadas na fase de aprofundamento, 12 são migrantes de outros estados, especialmente do Nordeste (5 - Ceará, Maranhã, Paraíba, Piauí) e Sudeste/ Sul (5 - Minas Gerais, Rio de Janeiro, São Paulo, Rio Grande do Sul) e dois do Centro-Oeste. Dos quatro entrevistados nascidos em Brasilia, os pais tinham origem no Sudeste e Nordeste. A média de idade daqueles que não nasceram em Brasília é de 47 anos, com média de tempo de moradia em Brasília igual a 31 anos. A média de idade dos brasilienses natos é 40 anos, o mais jovem com 29 anos.

Por ocasião das entrevistas, a maioria dos entrevistados exercia atividade remunerada, outra característica de intencionalidade da amostra. Pelas próprias características da cidade, metade é funcionário público e os demais têm ocupação em atividades administração, vendedor autônomo, enfermeiro e diarista. Quatro das entrevistadas são donas-de-casa, entre elas uma funcionária pública aposentada.

8 Período de aplicação dos questionários e realização das entrevistas: entre 27 /jul. e 27 /ago. de 2013.

9 Entrevistas agendadas com antecedência e realizadas na residência ou outro local de conveniência para o entrevistado.

10 Tópicos explorados nas entrevistas: vida em Brasília; consumo de mídia; práticas de consumo e lazer; vida social; ser cidadão. 
Com vistas a trazer uma análise mais concentrada no que foi o eixo do estudo, na sequencia exploro especificamente as respostas referentes às percepções (DSC resultado das perguntas abertas da etapa quantitativa) e às significações (síntese das formações discursivas coletadas nas entrevistas) expressadas pelos respondentes à intersecção consumo-cidadania.

A maioria dos respondentes $(95 / 150)^{11}$ afirma que "ter serviços de saúde e educação gratuitos" é o aspecto "mais importante para ser um cidadão", seguidos por 29/150 que dizem "ter liberdade para escolher os dirigentes políticos" e 26/150 "ter condições de escolher o que consumir para alimentação, vestuário, moradia". Respostas que refletem uma visão paternalista da relação Estado-população, com resquícios de uma "cidadania em negativa" (CARVALHO, 2009, p. 83) que promove a ação política da população apenas “em reação ao que é considerado arbítrio das autoridades".

"Ajudar a quem tem menos que você" foi opção de 74\% das respostas $(291 / 394)^{12}$ como sendo os principais deveres de um cidadão, "preservar o meio ambiente" resultou 16\%, enquanto $10 \%$ das escolhas foi "participar da vida política - votar, ter um partido político". Observamos que as opiniões sobre o que sejam "direitos" ("ter serviços de saúde e educação gratuitos") e "deveres" (“ajudar a quem tem menos que você") de certa forma se contradizem. No limite, as duas proposições fazem referência ao assistencialismo - ser ajudado e ajudar - um posicionamento ainda muito distante de uma concepção de cidadania que se aproxime da participação política e do compartilhamento da herança social.

Para os respondentes "consumir" é "uma necessidade" (92/150), "um direito" (52/150) e "um vício" (6/150). Perceber o consumo como "necessidade" indica a importância do estabelecimento de um espaço de poder, ainda que relativo na medida em que tem como base a posse de bens “finitos”. Um 'poder' que não passa pela ‘submissão do Outro', refletindo um novo consumidor-indivíduo que se percebe como parte da sociedade total que, embora não plenamente ciente do que isso signifique, já atenta para as possíveis brechas de agência político-social que se apresentam por meio do consumo.

11 Na exposição dos dados quantitativos, optei pelos valores absolutos tendo em vista que o estudo não teve como foco verificar relações estatísticas.

12 Nesta questão os respondentes podiam fazer até duas escolhas ("deveres" no plural), o que resultou, para os 150 respondentes, 394 respostas somando as três opções, daí o resultado expresso em porcentagem, sintetizando o que seria o "dever" principal. 
Fechando o foco no interesse do estudo, as respostas à "você se sente um(a) cidadão(ã) brasiliense? Por que?” explicitam a relação consumocidadania: posse da casa, constituição da família (e consequentemente aquisição do básico necessário para isso), formação escolar e oportunidade de crescimento profissional. Novamente um contraponto se retomarmos a referência de que "ser cidadão significa ter serviços de saúde e educação gratuitos". Dada a abertura para a livre expressão (pergunta aberta), "ser cidadão" fica por conta do trabalho individual, quanto muito da união familiar: é o "construir algo", valorizando-se o aspecto econômico-financeiro, ter um emprego, uma profissão. Uma posição coerente tendo em vista o entendimento do "consumo como direito", já exposto e que apenas confirma ser o consumo uma atividade social central da contemporaneidade, "não apenas porque a ele dedicamos grande parte de nossos recursos econômicos, temporais e emocionais, mas também porque é nele que se criam e estruturam grande parte de nossas identidades" (ALONSO, 2006, p. 30).

Outra parcela dos entrevistados se diz "cidadã" ou porque nasceu em Brasília ou porque aí constituiu sua família e é onde todos moram hoje. Compreensão muito próxima da comentada anteriormente, com ênfase na ocupação do espaço territorial (o morar), com indicadores de uma perspectiva que vai além da relação explícita das práticas. As falas "conseguimos dignidade" e "tenho o direito de escolher" me levam a relacionar cidadania com o exercício do direito de pertencimento que hoje, mais diretamente, passa pelo consumo ainda que pela via do estabelecimento de identidades fluidas.

Existem também aqueles que, apesar de morarem em Brasília e aí terem sua família e seu emprego, "não" se consideram “cidadãos brasilienses". Nesse caso, apesar da aparente diversidade de motivos - tempo de moradia, tradição familiar, custo de vida, clima -, arrisco dizer que há uma semelhança entre os motivos pessoais para mudança para Brasília: situações completamente fora do controle destes respondentes - por aprovação em concurso público; como a solução de problemas pessoais, além dos financeiros; como uma forma de se afastarem de situações difíceis, o que poucas vezes resulta em sucesso.

Para este grupo, as dificuldades e necessidades específicas e naturais decorrentes da mudança para uma nova cidade assumem significados mais concretos pois afetam diretamente a sobrevivência material no novo ambiente, especialmente na medida em que declaram que "o custo de vida é alto, existe muita diferença financeira". Manifestações que também apontam para a relação consumo-cidadania. 
Das entrevistas em profundidade, explorei os discursos sobre cidadania. O relato sobre "viver em Brasília", primeiro tópico, nos entrega uma descrição objetiva da cidade - bela, calma, ampla, organizada, moderna que, mesmo refletindo um imaginário institucionalmente construído, revela a forte inserção daqueles que "gostam" de lá estar, e que resulta em sentimentos diversificados dependendo da circunstância do entrevistado: ela é também "estranha", para o recém-chegado, "um lugar para viver" para o imigrante compulsório, enquanto o "nativo", jovem com menos de 35 anos, a ama incondicionalmente. Na palavra dos entrevistados:

[...] uma cidade que me deu tudo o que sou hoje, [...] condições de buscar os conhecimentos. [...] aqui dá pra gente viver feliz, principalmente pra trabalhar. Aqui só não trabalha aquele que não quer. [...] muitas oportunidades, de emprego, de cursos. [...] catar papelão dá dinheiro, catar latinha dá dinheiro, vender garrafa, vender ferro velho. [...] porque eu não nasci aqui, mas eu me sinto morador, eu me sinto do Distrito Federal. Aqui já sou avô, tenho três filhos. Eu tenho 40 anos de idade, fui avô muito cedo, meu neto tem 6 meses então pra mim é uma gloria. ${ }^{13}$

Para a primeira geração nascida em Brasília há uma cultura artística brasiliense em construção. Respondentes na faixa dos 30 anos expressam orgulho pela banda musical "Legião Urbana” e seu ícone, Renato Russo, ambos originários daquela cidade. Fenômeno que se concretiza na participação dos shows patrocinados pelas grandes empresas, trazendo os ritmos funk, samba, sertanejo, especialmente com artistas mais próximos do Centro-Oeste, muitas vezes sem expressão nos centros do Sudeste. Em uma dimensão mais oficial, visando à inserção social, instituições, escolares e comunitárias usam do rap para agregar jovens das RAs em torno de práticas culturais, especialmente pela carência de espaços de cultura, privados ou públicos. ${ }^{14}$ As oportunidades de trabalho compensam as dificuldades, tanto para aqueles que chegaram há mais de 30 anos, que cresceram com a cidade, cujas trajetórias de vida acompanharam os movimentos da cidade, sem uma profissão definida, mas que hoje têm famílias constituídas e filhos e netos estabelecendo-se profissionalmente, como para os mais jovens.

Eu acho que em Brasília é onde as pessoas têm um

13 Nestas transcrições agrupo falas de diversos entrevistados, resultado da busca pelas formações discursivas respondendo ao princípio do DSC.

14 Das 32 RAs, há cinemas apenas nos shoppings de Taguatinga-Sul e Sobradinho, RAs próximas do Plano Piloto, o que deixa, portanto, os extremos do DF totalmente carentes deste tipo de entretenimento. 
pouco mais de conhecimento político, e isso me dá orgulho. [...] me dá orgulho de Brasília justamente porque ela não é preconceituosa como eu vejo (pelo noticiário) as outras capitais. [...] sinto que sou um cidadão brasiliense, porque aqui eu vim com um sonho e acabei realizando um sonho maior.

Brasília não tem esquinas são todos os prédios do mesmo jeitinho, colocados ali, todos iguais, e se você for conhecer a fundo, cada quadra é diferente. Então, ser brasiliense é isso, é você ir pra casa passando pela ponte mais bonita do mundo, e depois você passa pelo Lago, que é uma maravilha, se eu for pelo Lago Sul [...] morar em Brasília é você andar no meio dos prédios e ao mesmo tempo andar no meio de um patrimônio histórico de preservação mundial.

O nosso comércio é muito rico, que gera muita renda. Existem vários ambulantes, existe o cara que vende churrasquinho e que sobrevive disso, cria famílias, paga a faculdade do filho vendendo churrasquinho $[. .$.$] tem uma vivência muito forte,$ as pessoas convivem muito e ela tem um comércio muito fortalecido você acaba tendo as grandes lojas que você tem na área central de Brasília você tem também nas cidades satélite. [...] Aqui a gente já conhece todo mundo.

Modo geral, e nem se esperava outra posição, todos se declaram satisfeitos com a cidade, o clima positivo de convivência social, as facilidades de comércio, representando até motivo de orgulho. Entretanto, há também o reconhecimento das dificuldades, descritas como mazelas decorrentes de um crescimento explosivo por quem se coloca externo a elas e (até) justificadas por aqueles que com isso sofrem mas que procuram amenizar no discurso, refletindo as superações vividas. Relatos sobre as dificuldades em relação ao transporte público são comuns, motivo que faz com que alguns prefiram pagar mais caro para morar no Plano Piloto, mas próximo de locais de trabalho e das opções de lazer, do que morar nas RAs, onde tudo é mais barato, mas com grande carência de transporte público, até com restrições de horário de funcionamento, além do serviço de saúde pública insuficiente.

Não adianta você pensar que vai se divertir dependendo do transporte público, porque deu meia-noite, acabou. [...] Nós temos um transporte público em Brasília muito inacessível, muito caro 
[...] Quando a gente realmente precisa, porque eu não tenho plano de saúde, então é o SUS mesmo, é bem dificultoso porque não é fácil enfrentar esses hospitais. [...] (nas RAs) tá muito difícil, não tem pronto socorro, não tem médico, não tem nada.

O custo (de vida) é muito alto, mas boa parte dos salários de Brasília cobre isso. [...] as coisas aqui no Plano são mais caras [...] se você for ali em Taguatinga, vai encontrar diferença de preço, se você for pra Ceilândia, vai encontrar mais barato ainda, lá na Samambaia você vai encontrar mais ainda. [...] Pra compras aqui (Paranoá) é muito bom, tem um comercio bem farto, os preços também é (são) compatível(ies) com a renda da gente, se comparando ao Plano Piloto. [...] Eu prefiro morar aqui no centro de Brasília, é um pouco mais caro, tenho a comodidade de ir pro meu trabalho que é daqui 5 minutos, economizo o meu tempo, meu combustível, meu carro.

Percebe-se uma relativização do bem-estar. Aqueles com maior acesso aos bens materiais, o que possibilita o acesso aos serviços de saúde, transporte pela via do privado, falam das necessidades do "outro", apontando os governantes como peça-chave para a solução, eximindo-se completamente como eventuais atores políticos. Já as pessoas com menor acesso relativizam, justificando a partir do ponto de vista de "cada um buscar" o que é de seu interesse, embora reconhecendo a carência do que lhe é oferecido, compensa a avaliação pela (relativa) facilidade em recorrer a quem tem poder, condições de encaminhamentos, para atender as necessidades de saúde, educação, serviços públicos em geral. Resta, assim, a quem tem pouca voz, expressão material, a voz coletiva, lembrando o quanto são valorizadas as relações sociais mais próximas, de parentesco, por este grupo.

A síntese da busca junto aos 16 entrevistados resulta uma compreensão de "cidadania" como um fenômeno a partir do qual as pessoas são "aceitas" na cidade, na sociedade onde convivem, mas também em parte dependente de ações "externas", do Estado no caso. Fica claro também uma relação 'naturalizada', mas não reconhecida verbalmente, entre cidadania e consumo na medida em que para "ser aceito", reconhecido nos seus direitos de "ir e vir", entrar nas lojas, instituições públicas e privadas, é preciso "estar apresentável”. Na relação com a mídia, à telenovela é imputada maior força de influenciar comportamentos, um espaço de educação mais importante até 
do que o familiar.

[...] tem muitos direitos que a gente consegue buscar e alcançar porque eu vejo que tem muitos lugares que não têm o que a gente tem aqui. (tem que ir atrás) Tem, e aqui no Distrito Federal, o que eu percebo, é que as pessoas escutam muito a gente [...] e aqui em Brasília é muito bom porque a gente tem contato às vezes com as pessoas que estão diretamente lá mexendo com o governo ou com uma coisa e outra porque isso também é importante porque se não a gente também não tem como chegar. [...] a gente tem que fazer valer o direito da gente assim como os deveres então tem que buscar os direitos. A gente também tem que dar muita opinião. A cidade é mais ou menos movida assim [...] tem que ir para o orçamento participativo e a gente tem que ir lá votar.

No âmbito da relação consumo-cidadania, esta é mencionada como um aspecto que colabora para "sentir-se bem na cidade", tanto por quem mora no Plano Piloto como por aqueles que lá "fizeram a vida". Na relação com o consumo, a consideração é de que 'realmente' vivemos uma ideologia do consumo, este constituído como uma parte da dinâmica estrutural da sociedade, salientando que o consumo do qual trato aqui é aquele que nos torna cidadãos, na linha de Garcia Canclini (1996), a partir do que demarcamos identidades e posições sociais.

A cidadania brasiliense é complicada de se adquirir porque a maioria não nasceu aqui [...] Você tem que ver a prática: veio para trabalhar, trabalhe, amizade, se der, é segundo plano. [...] Você ter um poder de consumo, você ter condições de comprar as coisas pra sua casa ou para os seus filhos. A auto estima elevada, você está praticando realmente, exercendo a sua cidadania, esse poder de compra, você ter autonomia. [...] Sim claro, pode você chegar no hospital e ser atendido. Você se sente cidadã, cidadão, você não se sente um mendigo implorando por uma obrigação do governo. [...] eu acho que o poder de compra realmente dá uma autonomia bem bacana pra pessoa, ela trabalhar, ela ter seu emprego e poder ir lá e comprar o que ela quiser e onde ela quiser.

Um discurso que retoma as descobertas da etapa quantitativa ao ratificar a compreensão do consumo como poder (autonomia), representando "a própria arena em que a cultura é objeto de lutas que lhe conferem forma" 
(DOUGLAS e ISHERWOOD, 2004, p. 103).

Com a pergunta "você se sente um cidadão brasiliense? Por quê?" visei a me aproximar de formações discursivas que mais objetivamente explicitassem a compreensão de "cidadania". O resultado foram afirmações marcadamente caracterizadas por uma identidade compartilhada:

[...] Eu me sinto cidadão brasiliense é quando posso contribuir com a minha comunidade, onde moro, que eu posso passar a minha experiência de vida e que eu posso ajudar de alguma maneira na formação daquele cidadão. [...] Eu me vejo Brasiliense, eu sou apaixonado por Brasília, [...] então é a imagem que eu vejo quando você fala em Brasília o que me vem na cabeça são os jovens com ideais que buscam melhorar a qualidade de vida de um modo geral da população, são jovens que batalham pelo que acreditam, são formadores de opiniões, que tem uma formação política muito forte [...].

$\mathrm{Na}$ fala dos entrevistados é visível a satisfação em morar em Brasília, nem tanto pelo que a cidade lhes oferece de facilidade, conforto, proteção, mas pela oportunidade de sobrevivência e progresso que sua construção possibilitou, especialmente em uma época, como historicamente sabemos, em que o Nordeste sofria as auguras das secas.

Aproximação final: da cidadania ao pertencimento, do consumo à identidade

O foco das reflexões aqui apresentadas foi a opinião dos indivíduossujeitos sobre a vida em Brasília do ponto de vista das atividades do diaa-dia a partir do que busquei compreender as significações atribuídas à cidadania, pensada para além da institucionalização de "direitos" e "deveres". No contexto da (con)vivência em uma sociedade de mercado, 'consumo' foi tomado como uma prática de cidadania, entendida como uma representação social resultante do compartilhamento de ideias.

Dos aspectos abrangidos pelo roteiro, destaquei as respostas aos itens mais relevantes, conforme bibliografia desenvolvida, para pensar a relação consumo-cidadania na sociedade da comunicação utilizando o DSC.

$\mathrm{Na}$ relação com o consumo, o resultado é um discurso muito forte "contra", o que analiso como reprodução da noção de "consumismo" 
difundida pela mídia, adquirindo por vezes até uma conotação patológica. Entretanto, quando vamos para as práticas no dia-a-dia, consumir é comentando como uma atividade corriqueira, necessária e até racionalizada dentro das expectativas do estilo e qualidade de vida dos entrevistados.

Sobre a relação comunicação-consumo-cidadania, as conclusões apontam para a explicitação e reconhecimento do consumo como constituinte das identidades, que proporciona um estado de cidadania, significando participação do indivíduo comum nos destinos da sociedade, ciente e agente de seu direito ao consumo simbólico e cultural, definido também pelo consumo material.

De Castells (2000,p.24) temos que "cada tipo de processo de construção de identidade leva a um resultado distinto no que tange à constituição da sociedade", sendo basicamente três os processos: legitimadora, de resistência e de projeto. No caso deste estudo, as manifestações dos respondentes ora revelam uma identidade legitimadora, ora de resistência. Independentemente da situação material, quando se colocam como porta-vozes da cidade que lhes acolheu, ou a seus pais, reproduzem o estabelecido pelas "fontes de dominação estrutural”, legitimando uma dinâmica de dominação.

Entretanto, no relato do fazer cotidiano, geralmente em terceira pessoa em um movimento de autoproteção, as narrativas transparecem a agremiação no coletivo, a busca do apoio comunitário "informal" para vencer as carências públicas e (sobre)viver em busca de dias melhores e/ou da manutenção das conquistas. 


\section{Referências}

ALONSO, Luis E.. La era del consumo. Madrid: Siglo XXI de España Editores, 2006.

BAUDRILLARD, Jean. A sociedade do consumo. Lisboa: Edições 70, 2007.

BAUMAN, Zygmunt. Identidade. Rio de Janeiro: Jorge Zahar Ed., 2005.

CARVALHO, José Murilo de. Cidadania no Brasil: o longo caminho. $6^{\text {a }}$ ed. Rio de Janeiro; Civilização Brasileira, 2004.

CASTELLS, Manuel. O poder da identidade - a era da informação: economia, sociedade e cultura. Vol.2. São Paulo: Paz e Terra, 2000.

CERQUIER-MANZINI, Maria L.. O que é cidadania. São Paulo: Brasiliense. Coleção Primeiros Passos, 2010.

DOUGLAS, Mary e ISHERWOOD, Baron. O mundo dos bens - para uma antropologia do consumo. Rio de Janeiro: Editora UFRJ, 2004.

FREDERICO, Celso. O consumo nas visões de Marx. In: BACCEGA, Maria Ap. (Org.). Comunicação e culturas do consumo. São Paulo: Atlas, 2008, pp. 79-87.

GARCIA CANCLINI, Néstor. Consumidores e cidadãos - conflitos multiculturais da globalização. Rio de Janeiro: UFRJ, 1996.

JODELET, Denise (Org.). As representações sociais. Tradução de Lilian Ulup. Rio de Janeiro: UERJ, 2001.

LEFEVRE, Fernando e LEFEVRE, Ana Maria Cavalcanti. Curso teóricoprático de introdução ao Discurso do Sujeito Coletivo e ao software QualiQuantiSoft. São Paulo: IpDsc-Instituto de Pesquisa do Discurso do Sujeito Coletivo, 2013. MOSCOVICI, Serge. Representações sociais - investigações em psicologia social. 9ª edição. Petrópolis (RJ): Vozes, 2012. 